\title{
Synthesis of crispine A analogues via an intramolecular Schmidt reaction
}

\author{
Ajoy Kapat, Ponminor Senthil Kumar and Sundarababu Baskaran ${ }^{*}$
}

\section{Full Research Paper}

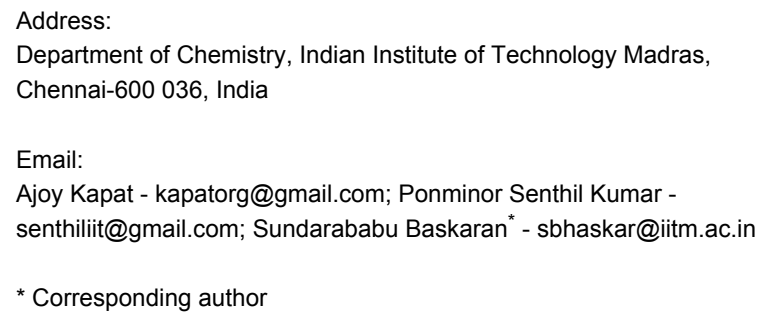

Beilstein Journal of Organic Chemistry 2007, 3, No. 49 doi:10.1186/1860-5397-3-49

Received: 16 October 2007

Accepted: 19 December 2007

Published: 19 December 2007

(C) 2007 Kapat et al; licensee Beilstein-Institut

License and terms: see end of document.

\section{Abstract}

An intramolecular Schmidt reaction strategy for the synthesis of various derivatives of crispine A using azido-ketone as a key intermediate is described.

\section{Background}

The indolizidine skeleton is one of the most important structural subunits present in numerous biologically active molecules. [1-4] The polyhydroxylated indolizidines are potent inhibitors of carbohydrate processing enzymes and hence they are considered to be lead drug molecules in the treatment of metabolic diseases such as diabetes, cancer and HIV infection. [5-7] The alkyl indolizidine alkaloids, also called gephyrotoxins, are well-known for their ability to function as noncompetitive blockers of neuromuscular transmission [2] by interacting with nAChRs. In addition, the indolizidine skeleton is also present in anticancer molecules such as lepadiformine,[8] antofine,[9] and tylophorine [9] as well as a immunosuppressive agent, FR901483.[10] The wide range of biological activities associated with the indolizidine alkaloids has elicited considerable interest in them as target molecules among synthetic organic chemists. As a result, numerous synthetic approaches have been developed for the synthesis of indolizidine alkaloids. [5-7] One of the most efficient methods for the construction of the indolizidine framework is based on the intramolecular Schmidt reaction of azides with carbonyl compounds.[11,12] Pearson and Aube have exploited the synthetic potential of the intramolecular Schmidt reaction in the synthesis of several indolizidine alkaloids. [11-15]

Recently, we reported a novel approach for the construction of the indolizidine skeleton using an epoxide initiated electrophilic cyclization of azide as a key step. This novel methodology has been efficiently applied in the stereo- and enantioselective synthesis of indolizidine 167B and 209D (Scheme 1). [16-18]

\section{Results and discussion}

In 2002, a new indolizidine alkaloid known as crispine A was isolated from Carduus crispus, a popular invasive plant occurring in Asia and Europe, which was found to exhibit superior antitumor activity against SKOV3, KB and HeLa human cancer lines.[19] As a result of its potent antitumor activity, various synthetic methods have been developed for the 


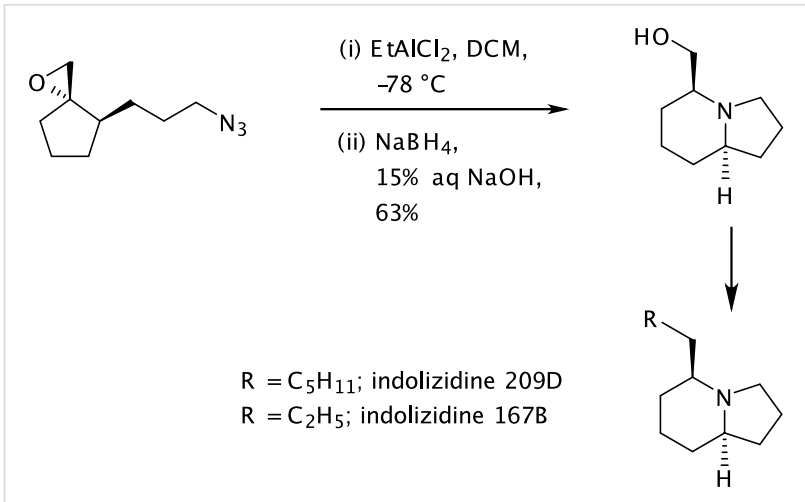

Scheme 1: Epoxide initiated electrophilic cyclization of azide.

synthesis of crispine A. [20-28] Interestingly, Schell and Smith reported the first synthesis of crispine $\mathrm{A}$, even before its isolation, using the $\mathrm{N}$-chloramine rearrangement reaction as a key step.[25] In order to understand the structure activity relationship (SAR) as well as to improve the efficacy of this novel anticancer agent, a flexible approach for the synthesis of various derivatives of crispine $\mathrm{A}$ is in great demand (Scheme 2).<smiles>COc1cc2c(cc1OC)C1CCCN1CC2</smiles>

Crispine A

1<smiles>COc1cc2c(cc1OC)C1(C(=O)O)CCCN1C(=O)C2</smiles>

$3 \mathrm{R}=\mathrm{Me}, \mathbf{3 a} \mathrm{R}=\mathrm{Et}$ $4 \mathrm{R}=\mathrm{H}$<smiles>COc1cc2c(cc1OC)C1(C)CCCN1CC2</smiles>

2

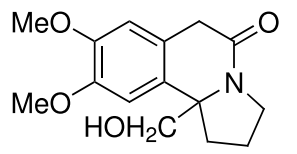

5
Scheme 2: Crispine A and its analogues.

In 2000, Pearson reported the intramolecular Schmidt reaction based approach for the construction of benzo-fused indolizidine skeleton using azido-olefin as a key intermediate (Scheme 3). In this reaction, in addition to benzo[ $e]$ indolizidine $\mathbf{A}$, a minor product $\mathbf{B}$ having the basic skeleton of crispine A was isolated in $28 \%$ yield. The intramolecular Schmidt reaction of azidoolefin in the presence of triflic acid proceeds with aryl migration rather than alkyl migration resulting in the formation of benzo[e]indolizidine [A] as a major product (Scheme 3).[29]

In this communication, we report the synthesis of crispine A analogues (2-5) using an intramolecular Schmidt reaction of azidoketone $\mathbf{6}$ as a key step. The azidoketone $\mathbf{6}$ can be readily

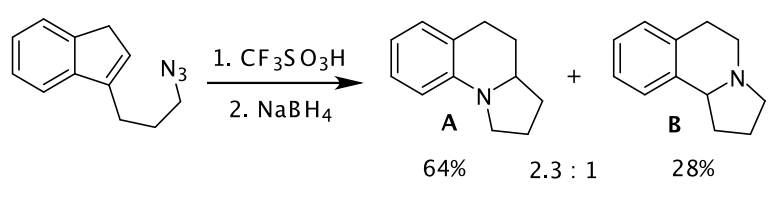

Scheme 3: Intramolecular Schmidt reaction of olefin azide.

prepared from the $\beta$-ketoester 7 , which in turn can be synthesized from the dimethoxybenzoic acid $\mathbf{8}$ as shown in Scheme 4.[30] 3,4-Dimethoxybenzoic acid (8) on treatment with paraformaldehyde in the presence of conc. $\mathrm{H}_{2} \mathrm{SO}_{4}$ followed by reduction with LAH gave the corresponding diol 9 as a white crystalline solid. Diol 9 on bromination followed by nucleophilic displacement with $\mathrm{NaCN}$ furnished the desired dicyano compound $\mathbf{1 0 .}$

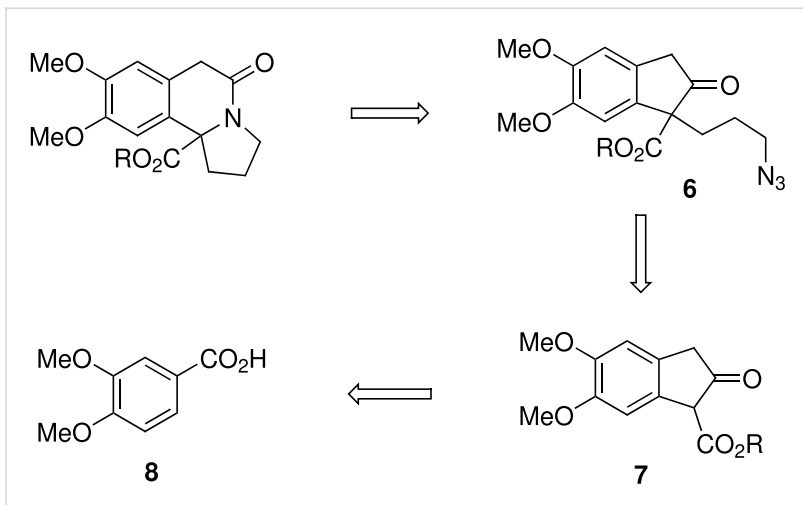

Scheme 4: Retrosynthetic approach for crispine A analogues.

Treatment of dicyanide $\mathbf{1 0}$ with thionyl chloride in methanol gave the corresponding diester $\mathbf{1 1}$ as a colorless liquid in good yield. Compound 11 was then readily converted to the corresponding $\beta$-ketoester 7 via Dieckmann cyclization and the resultant product was purified by recrystallization using $\mathrm{H}_{2} \mathrm{O}$ EtOH solvent system (Scheme 5).

Our attempts towards the alkylation of $\beta$-ketoester 7 with 1-chloro-3-iodopropane under different reaction conditions were ineffective and resulted in poor yield. In order to improve the yield of the alkylation reaction, compound 7 was protected as the corresponding ethylene ketal 12 (Scheme 6).

Surprisingly, alkylation of ketal-ester 12 using $\mathrm{NaH}$ in dry DMF proceeded smoothly even at room temperature, however it resulted in an unusual cleavage of ethylene ketal under basic conditions, leading to hydroxy vinylether $\mathbf{1 3}$ in $70 \%$ yield. The formation of hydroxy vinylether $\mathbf{1 3}$ is evident from the spectroscopic data. The presence of a sharp singlet at $\delta_{\mathrm{H}} 5.66(\mathrm{~s}, 1 \mathrm{H})$ in ${ }^{1} \mathrm{H}$ NMR and signals corresponding to vinyl carbons $\left(\delta_{\mathrm{c}}\right.$ 


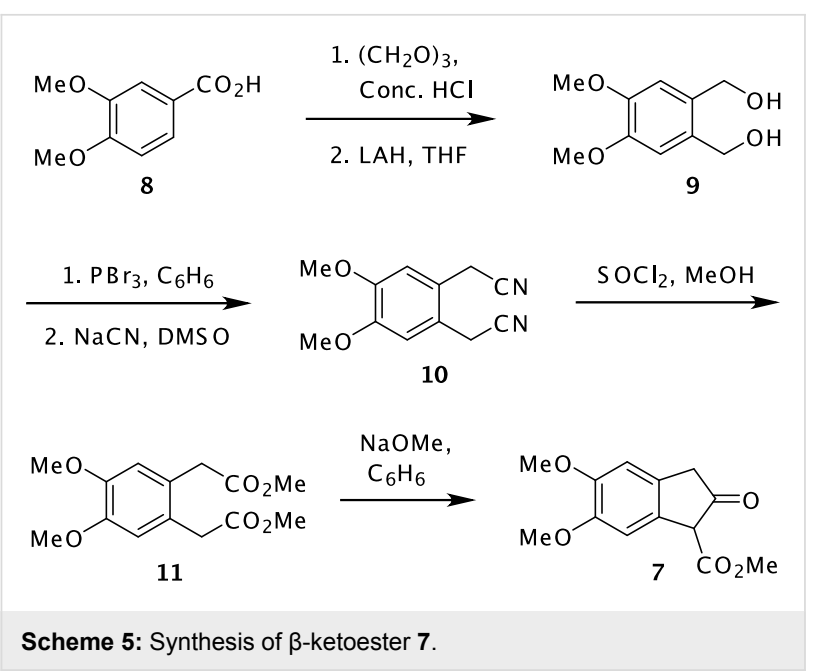

104.28, 164.39) in ${ }^{13} \mathrm{C}$ NMR, as well as an absorption at 3513 $\mathrm{cm}^{-1}$ in IR spectrum, clearly indicate the presence of a vinylether and a free hydroxyl group in compound 13. Reaction of hydroxy vinylether $\mathbf{1 3}$ with acetic anhydride yielded readily the corresponding acetate derivative $\mathbf{1 4}$ which further supported the formation of hydroxy vinylether under basic conditions (Scheme 6).

Reaction of 13 with $\mathrm{NaN}_{3}$ gave the corresponding azido derivative 15 which on further treatment with DOWEX ${ }^{\circledR} 50 \mathrm{WX} 8 \mathrm{H}^{+}$ in methanol under reflux conditions afforded the corresponding azido-ketone 6 in $81 \%$ yield (Scheme 7).

Finally, the intramolecular Schmidt reaction of azido-ketone 6 was successfully achieved using $\mathrm{TfOH}$ at -5 to $0^{\circ} \mathrm{C}$ and the resultant cyclized product, indolizidine derivative $\mathbf{3}$, was isolated in 54\% yield (Scheme 8). Similarly, the indolizidine derivative $\mathbf{3 a}$ was prepared from the dicyanide $\mathbf{1 0}$.

The structure of indolizidine derivative 3 was established by 1D and 2D NMR analyses which was unambiguously further
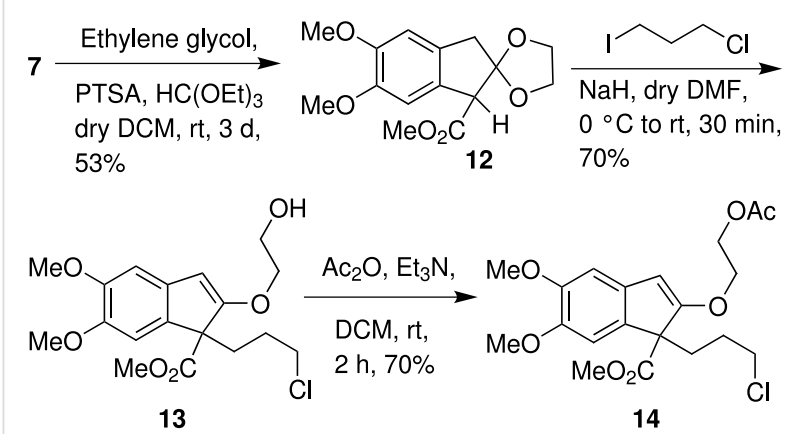

Scheme 6: Alkylation of ketal-ester 12.
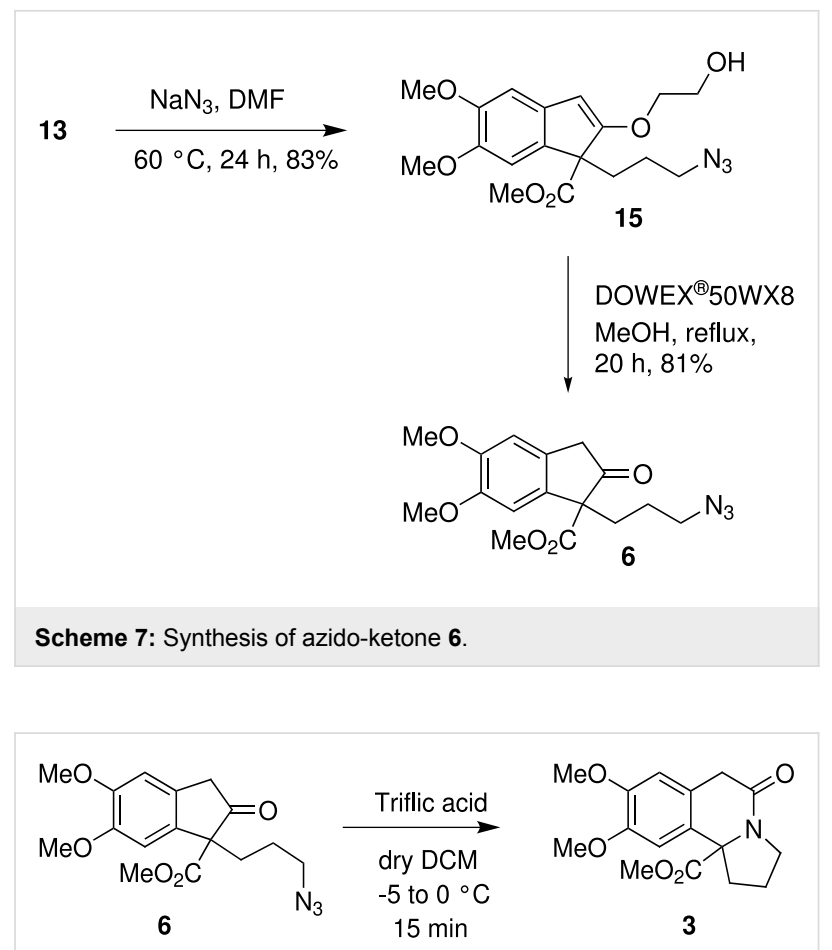

Scheme 8: The intramolecular Schmidt cyclization of azido-ketone 6.

confirmed by single crystal X-ray analysis (Figure 1), on the corresponding acid derivative 4 (Scheme 9).

After achieving the construction of the indolizidine skeleton using the intramolecular Schmidt reaction, our next objective was to prepare various derivatives of the anti-cancer agent, crispine A, starting from the key intermediate 3. Consequently, the ester functional group of the indolizidine derivative 3 was reduced with $\mathrm{LAH}$ in dry THF at $0^{\circ} \mathrm{C}$ to give the corresponding hydroxymethyl derivative 5. Mesylation of 5 with mesyl

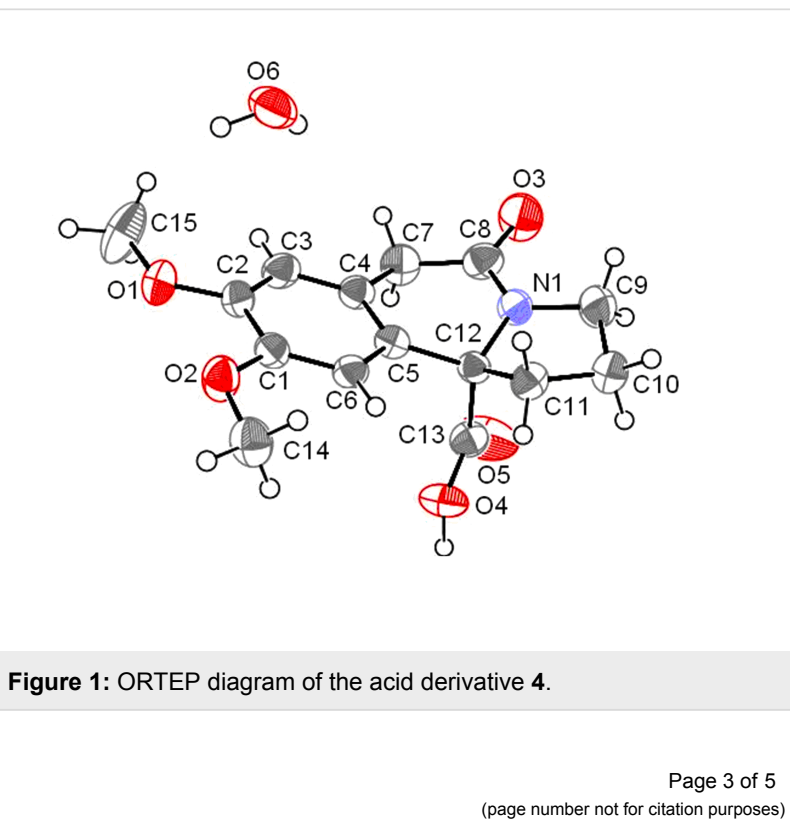




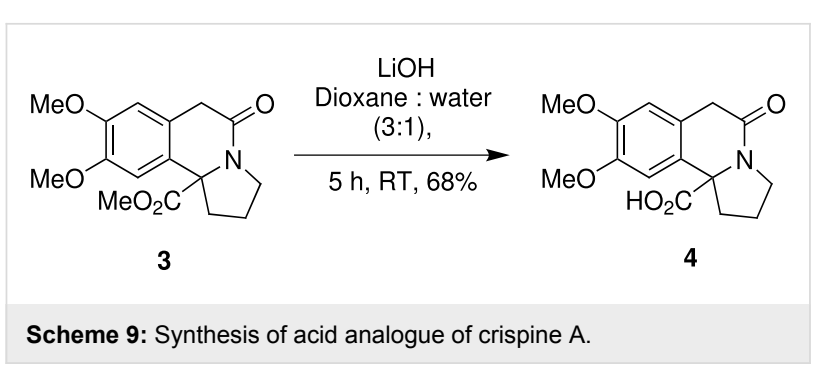

chloride and triethylamine yielded the corresponding lactam $\mathbf{1 6}$ which on further exposure to $\mathrm{LAH}$ in the presence of conc. $\mathrm{H}_{2} \mathrm{SO}_{4}$ [20] gave the methyl analogue of crispine A (2) in $80 \%$ yield (Scheme 10). Spectral data of compound 2 were found to be in complete agreement with the reported values.[26] (See Supporting Information File 1 for full experimental data)

$$
3 \underset{\mathrm{rt}, 8 \mathrm{~h}, 70 \%}{\stackrel{\mathrm{LAH}, \mathrm{dry} \mathrm{THF},}{\longrightarrow}}
$$<smiles>COCC1(OCCO)CCN2C(=O)Cc3cc(OC)c(OC)cc3C21COC</smiles>

Scheme 10: Synthesis of methyl analogue of crispine A.

\section{Conclusion}

In conclusion, we have successfully achieved the synthesis of various derivatives of crispine A (2-5), starting from the azido ketone 6, using the intramolecular Schmidt reaction as a key step. The structure of the cyclized indolizidine derivative $\mathbf{3}$ was unambiguously confirmed by single crystal X-ray analysis. Interestingly, an unusual cleavage of ethylene ketal to vinylether was observed during the alkylation of ketal-ester $\mathbf{1 2}$ Since the compounds $\mathbf{5}$ and $\mathbf{1 6}$ are highly functionalized intermediates, they can be further exploited in the synthesis of a library of anti-cancer analogues. The structure activity relationships (SAR) and anti-cancer activities of our synthetic derivatives will be reported in due course of time.

\section{Supporting Information}

\section{Supporting Information File 1}

Experimental section. Experimental data, which includes experimental procedures and spectral data.

[http://www.beilstein-journals.org/bjoc/content/ supplementary/1860-5397-3-49-S1.pdf]

\section{Acknowledgments}

We thank DST (New Delhi) for financial support and the DSTFIST program for NMR facility. P.S.K (SRF) thanks CSIR (New Delhi) for a research fellowship.

\section{References}

1. Daly, J. W. J. Nat. Prod. 1998, 61, 162-172. doi:10.1021/np970460e

2. Daly, J. W.; Sande, T. F. In Alkaloids: Chemical and Biological Perspectives; Pelletier, S. W., Ed.; Wiley: New York, 1986; Vol. 4, Chapter 1.

3. Aronstam, R. S.; Daly, J. W.; Spande, T. F.; Narayanan, T. K.; Albuquerque, E. X. Neurochem. Res. 1986, 11, 1227-1240. doi:10.1007/BF00965950

4. Michael, J. P. In The Alkaloids: Chemistry and Pharmacology; Cordell, G. A., Ed.; Academic Press: New York, 2001; Vol. 55, pp 91 ff.

5. Michael, J. P. Nat. Prod. Rep. 2005, 22, 603-626. doi:10.1039/ b413748p

6. Michael, J. P. Nat. Prod. Rep. 2004, 21, 625-649. doi:10.1039/ b310689f

7. Michael, J. P. Nat. Prod. Rep. 2002, 19, 719-741. doi:10.1039/ b104969k

8. Sauviat, M.-P.; Vercauteren, J.; Grimaud, N.; Jugé, M.; Nabil, M.; Petit, J.-Y.; Biard, J. F. J. Nat. Prod. 2006, 69, 558-562. doi:10.1021/ np050215s

9. Fu, Y.; Lee, S. K.; Min, H.-Y.; Lee, T.; Lee, J.; Cheng, M.; Kim, S. Bioorg. Med. Chem. Lett. 2007, 17, 97-100. doi:10.1016/ j.bmcl.2006.09.080

10. Sakamoto, K.; Tsujii, E.; Abe, F.; Nakanishi, T.; Yamashita, M.; Shigematsu, N.; Izumi, S.; Okuhara, M. J. Antibiot. 1996, 49, 37-44.

11. Lang, S.; Murphy, J. A. Chem. Soc. Rev. 2006, 35, 146-156. doi:10.1039/b505080d

12. Nyfeler, E.; Renaud, P. Chimia 2006, 60, 276-284. doi:10.2533/ 000942906777674714

13. Wrobleski, A.; Sahasrabudhe, K.; Aube, J. J. Am. Chem. Soc. 2004, 126, 5475-5481. doi:10.1021/ja0320018 And references cited therein.

14. Pearson, W. H.; Hutta, D. A.; Fang, W. J. Org. Chem. 2000, 65, 8326-8332. doi:10.1021/jo001181q

15. Pearson, W. H.; Walavalkar, R. Tetrahedron 2001, 57, 5081-5089. doi:10.1016/S0040-4020(01)00353-2

16. Reddy, P. G.; Varghese, B.; Baskaran, S. Org. Lett. 2003, 5, 583-585. doi:10.1021/ol027563v

17. Reddy, P. G.; Baskaran, S. J. Org. Chem. 2004, 69, 3093-3101. doi:10.1021/jo035258x

18. Reddy, P. G.; Sankar, M. G.; Baskaran, S. Tetrahedron Lett. 2005, 46, 4559-4561. doi:10.1016/j.tetlet.2005.05.008

19. Zhang, Q.; Tu, G.; Zhao, Y.; Cheng, T. Tetrahedron 2002, 58, 6795-6798. doi:10.1016/S0040-4020(02)00792-5

20. King, F. D. Tetrahedron 2007, 63, 2053-2056. doi:10.1016/ j.tet.2006.12.041

21. Bailey, K. R.; Ellis, A. J.; Reiss, R.; Snape, T. J.; Turner, N. J. Chem. Commun. 2007, 3640-3642. doi:10.1039/b710456a

22. Szawkało, J.; Zawadzka, A.; Wojtasiewicz, K.; Leniewski, A.; Drabowicz, J.; Czarnocki, Z. Tetrahedron: Asymmetry 2005, 16, 3619-3621. doi:10.1016/j.tetasy.2005.10.007

23. Knölker, H.-J.; Agarwal, S. Tetrahedron Lett. 2005, 46, 1173-1175 doi:10.1016/j.tetlet.2004.12.066

24. Orito, K.; Matsuzaki, T.; Suginome, H. Heterocycles 1988, 27 , 2403-2412. 
25. Schell, F. M.; Smith, A. M. Tetrahedron Lett. 1983, 24, 1883-1884. doi:10.1016/S0040-4039(00)81796-7

26. Okamoto, S.; Teng, X.; Fujii, S.; Takayama, Y.; Sato, F. J. Am. Chem. Soc. 2001, 123, 3462-3471. doi:10.1021/ja004140k

27. Allin, S. M.; Gaskell, S. N.; Towler, J. M. R.; Bulman Page, P. C.; Saha, B.; McKenzie, M. J.; Martin, W. P. J. Org. Chem. 2007, 72, 8972-8975. doi:10.1021/jo071235x

28. Manteca, I.; Sotomayor, N.; Villa, M.-J.; Lete, E. Tetrahedron Lett. 1996, 37, 7841-7844. doi:10.1016/0040-4039(96)01745-5

29. Pearson, W. H.; Fang, W. J. Org. Chem. 2000, 65, 7158-7174. doi:10.1021/jo0011383

30. Taylor, J. B.; Lewis, J. W.; Jacklin, M. J. Med. Chem. 1970, 13, 1226-1227. doi:10.1021/jm00300a050

\section{License and Terms}

This is an Open Access article under the terms of the Creative Commons Attribution License

(http://creativecommons.org/licenses/by/2.0), which permits unrestricted use, distribution, and reproduction in any medium, provided the original work is properly cited.

The license is subject to the Beilstein Journal of Organic Chemistry terms and conditions:

(http://www.beilstein-journals.org/bjoc)

The definitive version of this article is the electronic one which can be found at: doi:10.1186/1860-5397-3-49 